\title{
INTEGRAÇÃO E REPRESENTATIVIDADE: AÇÃO/RAZÃO COMUNICATIVA NO ESTADO DEMOCRÁTICO DE DIREITO
}

\author{
Rafaela Carqueijeiro Moro \\ Centro Universitário Eurípedes de Marília - UNIVEM. E-mail:rafaela.cm96@gmail.com \\ Bolsista pelo CNPq
}

\section{RESUMO}

O estudo em questão apresenta em seu alicerce fundamental o desenvolvimento de pesquisas na área do direito, sobretudo na área da filosofia do direito, com uma atenção especial, voltada para as abordagens feitas por teóricos da filosofia contemporânea, principalmente naquilo que se refere à razão comunicativa - portanto, Jürgen Habermas -, apresentando o direito como medium, em seu papel fundamental na integração social. Desta forma, aprimoramos o destaque quanto às propostas à crise de representatividade instalada no cenário brasileiro atual, não deixando de abordar os recentes eventos mundiais, que vêm demonstrando a necessidade da adoção de medidas menos violentas e que, de uma vez por todas, atendam às expectativas de paz. $\mathrm{O}$ artigo pretende, em sua base, ofertar e estimular a reflexão crítica, pautando nas teorias habermasianas uma forma de solução aos conflitos do mundo da vida.

Palavras-chave: Direito. Democracia. Crise do Estado de direitos. Razão comunicativa. Judicialização.

\section{INTEGRATION AND REPRESENTATIVENESS/ COMMUNICATIVE ACTION/REASON IN THE DEMOCRATIC STATE OF LAW}

\begin{abstract}
This study shows in its essential foundation the development of researches in the area of Law, overall in the area of Philosophy of Law, with a special attention to the approaches made by theoriticians of the contemporary philosophy, mainly in what refers to the communicative action - therefore, Jürgen Habermas -, showing Law as medium, in its essential rule in the social integration. This way, we improve the featured related to the proposals to representativeness crisis seated in the current Brazilian scenario, not letting to approach the recent events worldwide, that have been demonstrating the need of adoption of less violent measures and that, once for all, attend to the expectations of peace. The article intends, on its basis, to offer and stimulate the critical reflection, scheduling in the habermasian theories a way of soluctin to the conflicts in the lifeworld.
\end{abstract}

Keywords: Law. Democracy. Crisis of the State of Law. Communicative reason. Judicialization. 


\section{INTRODUÇÃO}

Ao tratar, em suas obras "Direito e democracia - Entre facticidade e validade" (2003a e b), da matéria do direito, bem como do viés democrático na sociedade atual, Jürgen Habermas atribui, àquele, função integradora social, de regulamentação das ações em prol do ordenamento das relações interpessoais, observando profundamente sua tensão com o Estado - bem como entre a facticidade e validade dentro dos sistemas atuais - concluindo-se no próprio Estado Democrático de Direitos (DURÃO, 2009, p. 119).

Dentro deste contexto, Habermas observa e analisa a necessidade de uma democracia em sua forma radical, dado o cenário de complexidade apresentado pelas sociedades atuais, atentando para a necessidade de os Estados Democráticos adaptarem-se à realidade. A base política tem sua legitimidade embasada no direito, que, por seu caráter instrumental, constrói um ordenamento às ações coletivas, dotado de um poder de coação (HABERMAS, 2003a, p. 170), estando, desta forma, atrelado à garantia dos direitos e dignidade humana.

A tensão intrincada na reciprocidade entre as funções da política e do direito, culmina numa derrocada do Estado de Direitos; tomando a crise da representatividade, dentro deste cenário, há que, ao menos, citar-se a judicialização do Estado (DWORKIN, 2002, p.225-227), a necessidade do indivíduo, em suas relações interpessoais e entre indivíduo e Estado, de recorrer ao Poder judiciário para fazer valer seus direitos em contrapartida à negligência dos outros poderes; esse desequilíbrio nas relações contidas no ideal de divisão igualitária e harmônica entre os poderes denota a necessidade da mediação por parte do direito e seu medium linguístico visando uma compreensão intersubjetiva.

Desta forma, faz-se necessária a compreensão da instrumentalização do direito moderno, sua função organizacional, reforçando a ideia de que fornece à política a base legitimadora dentro de um parâmetro de sua tensão com o direito (HABERMAS, 2003a, p. 44-45); ao analisar o uso efetivo da linguagem, Habermas observa seu uso performativo dentro das sociedades modernas com base em um potencial racional de reconhecer, compreender e solucionar conflitos dentro destas através da razão comunicativa, estrutura fundada na intersubjetividade e aperfeiçoada por citado uso da linguagem. Os indivíduos, desta maneira, por meio de uma integração às discussões racionais, têm a possibilidade de estabelecer diálogos e acessar os argumentos com pressupostos de validade criticáveis, na chamada ética do discurso, que fornece bases para um discurso democrático e baseado no respeito à intersubjetividade, na aproximação dos meios de vivência dos indivíduos.

Destarte, observamos a intersubjetividade conferida aos indivíduos em uma socialização horizontal, no que tange os discursos jurídicos (DURÃO, 2009, p. 119-120), bem como a inserção do direito em sua função integradora e mediadora de interações, ponto-chave do trabalho.

\section{METODOLOGIA}

A metodologia compõe-se, basicamente, uma análise bibliográfica aprofundada, sobretudo das obras de Jürgen Habermas, de forma que se fizesse a interligação com dados empíricos, principalmente no que tange o cenário político e jusfilosófico atual, passando pelas teorias da comunicação de Habermas, chegando, assim, a um resultado mais claro e concreto.

Naquilo que se refere aos objetos de estudo, pretendemos apresentá-lo ao leitor de forma a instigar, estimular e incentivar sobretudo o pensamento crítico. Da mesma forma, os resultados consistem numa concatenação das ideias centrais do trabalho, que sejam: a racionalidade, a estrutura da teoria do discurso e o cenário jurídico, político e filosófico - essencialmente o brasileiro, culminando na abertura de um pensamento racional como proposta de solução principalmente no que se refere à ação comunicativa. 


\section{RESULTADOS}

À luz dos pressupostos já pertinentes em uma análise empírica, há que se pensar em uma solução à crise de representatividade evidente no país, contida no formato corrompido do Estado democrático de direitos e que se configura em um cenário de descrença por parte dos próprios indivíduos, que não se reconhecem como autores e destinatários das normas instituídas, problemática analisada por Habermas (2003a e b).

Ressalta-se que o filósofo faz uma observação ao sistema jurídico moderno (2003a, p. 27), no sentido que este, em sendo um instrumento, mesmo que ambíguo, de integração social, pode e deve atribuir uma organização, frente à dificuldade de alcançar o pleno entendimento e compreensão; a partir o momento em que se obtém a efetiva comunicação e compreensão das ideias e ideais da sociedade e que têm os indivíduos as características tanto de destinatários como emissores das vontades, que resultam na legitimação da vontade social, estaríamos frente à representatividade de fato, que necessitamos. Para tanto, compreende-se a razão comunicativa como proposta de solução frente aos dissensos, pelo medium linguístico, dentro do contexto do sistema do direito.

Observa-se de forma clara o desequilíbrio nas relações entre os poderes, do sistema de pesos e contrapesos harmonizados de forma que pudessem o Judiciário, Legislativo e Executivo regularem-se entre si de forma pacífica e ordenada. Neste cenário, consequentemente, até mesmo o Estado é responsável por violar direitos humanos; na tentativa de regular essa tensão e assegurar os direitos inerentes aos cidadãos, surge como "solução" a medida intervencionista do sistema jurídico, a sobreposição do judiciário, há uma aproximação do direito com os indivíduos, para conter os conflitos gerados até mesmo pelos poderes.

\section{DESENVOLVIMENTO}

Assim explica Habermas o conceito de agir comunicativo:

"O conceito de agir comunicativo, que leva em conta o entendimento linguístico, como mecanismo de coordenação da ação, faz com que as suposições contrafactuais, dos atores que orientam seu agir por pretensões de validade adquiriram relevância imediata para a construção e manutenção de ordens sociais: pois estas mantém-se no modo de reconhecimento de pretensões de validade normativas. Isso significa que a tensão entre facticidade e validade, embutida na linguagem e no uso da linguagem, retorna ao modo de integração de indivíduos socializados comunicativamente - devendo ser trabalhado pelos participantes. Essa tensão é estabilizada de modo peculiar na integração social realizada por intermédio do direito positivo" (2003a, p.35).

Isto posto, há que se desenvolver uma crítica no sentido da composição de uma linguística com base habermasiana no que tange a razão comunicativa, amplificando-se nos parâmetros sociais da representatividade e Estado democrático de direitos. Através de sua teoria, Habermas demonstra a necessidade de reconhecimento dos indivíduos dentro das relações interpessoais, preservando a subjetividade de cada um, ao mesmo tempo em que se insere em discussões de conteúdo racional, compostos de discursos de embasamento racional (2003a, p. 35).

Partindo dessas premissas, observa-se a possibilidade de que os sujeitos encontrem a solução de conflitos em um consenso - através da intersubjetividade -, o reconhecimento e aceitação de proferimentos com pretensão de validade racionalmente criticáveis. (HABERMAS, 1990, p. 77). De forma sucinta, o autor explica:

"A teoria do agir comunicativo tenta assimilar a tensão que existe entre facticidade e validade [...] preservando, de um lado, o engate na 
interpretação clássica de um nexo entre sociedade e razão [...] e, de outro, não abandona a condução consciente na vida." (HABERMAS, 2003a, p. 25).

Faz-se necessária neste tópico, ainda que de forma breve, a diferenciação com relação aos âmbitos de autonomias pública e privada; desta forma, em uma objetiva definição, é possível assimilar a primeira à soberania popular, de forma a destacar a questão da cidadania e participação na esfera pública (SILVA, 2015, p. 166); a segunda, por sua vez, caracteriza-se pelo ideal da autonomia, baseada no exercício dos direitos civis, como autores e destinatários dos direitos, sendo fundamental, para Habermas, que os indivíduos assim se reconheçam (HABERMAS, 2003a, p. 157).

Tomados estes pressupostos, desdobrando as questões à luz da razão comunicativa e tendo o mundo da vida como subjacente a estas, é possível analisar a democracia e representatividade como ideais de interligação e não tão-somente, mas de autocompreensão dos indivíduos nelas concernidos.

Desta forma, objetivando a compreensão do cenário em que os indivíduos (sujeitos de direitos) estão inseridos, interligando as características nele contidas, apresenta-se proposta de solução, fundamentalmente no que se refere à crise do Estado democrático de direitos e sua consequente deficiência na estrutura de representatividade; proposta essa feita mediante, principalmente, o estudo da teoria habermasiana de ação/razão comunicativa.

De forma sintética, a proposta da razão comunicativa é, através de um processo intersubjetivo de discussão racionalmente mediado, atingir os fins de consenso entre os indivíduos, tendo naquele assegurada a subjetividade dos indivíduos envolvidos no dissenso; isto, em contraposição à razão estratégica, na qual observa-se que os fins já estão definidos.

Destarte, visando à inserção das premissas apresentadas de maneira a definir um parâmetro do direito moderno e tendo este como integrador de massas e indivíduos (HABERMAS, 2003a, p. 25), a um fim composto na efetividade da democracia, o cumprimento dos preceitos democráticos dentro do Estado de direitos.

A análise aprofundada da sociedade atual, no que tange o Estado democrático de direitos e sua efetividade, fundando-se na interligação das bases teóricas e empíricas ao objeto, havendo, possibilita que se apresente a razão comunicativa como norteadora aos dissensos a fim de sua resolução. $O$ desenvolvimento de uma discussão é de suma importância, sendo imprescindível instigar os destinatários/participantes a, também, refletir, despertando as análises críticas, que, além de enriquecer o debate, atingiriam um dos objetivos deste artigo, a saber, o raciocínio (razão), levando ao consequente aprimoramento das discussões e o encaminhamento destas a um parâmetro de entendimento.

Tomando o direito em sua forma integradora, há que se apresentar sua função composta e entrelaçada ao medium linguístico como intrínseca às relações interpessoais e entre indivíduo e Estado (HABERMAS, 2003a, p. 44-45).

Neste ínterim, dentro da perspectiva de Estado Democrático de Direito, retomamos o fato de estabelecer-se nos direitos humanos o elo fundamental entre as esferas pública.

Estabelecidos os parâmetros e analisado o evidente cenário de descrença para com a estabilidade social e democrática - e, assim, também, a legitimidade - por parte dos próprios indivíduos nela inseridos, complementar à desigualdade da sociedade moderna, integra-se o medium do direito como um "instrumento de colonização do mundo da vida", pertinente ao que define-se por "juridificação", mais especificamente em se tratando do mundo da vida, sofrendo as relações interpessoais cada vez mais interferência daquela. (DURÃO, 2008).

Destarte, observa-se a necessidade de se atingir um grau de representatividade por parte dos indivíduos - atores sociais -, cuja exteriorização pode ser percebida na busca do poder judiciário, a assegurar a dignidade humana e efetivação dos direitos àqueles inerentes. Assim, a judicialização, apresenta-se - resultando no desequilíbrio dos poderes -, de forma 
paradoxalmente necessária. Podemos, por conseguinte, retomar o papel do direito moderno como estabilizador das relações, como afirma Habermas.

Indispensavelmente, a abordagem da razão comunicativa reafirma-se como suporte à problemática apresentada. A partir da intersubjetividade e a coordenação das ações inseridas em uma premissa de consenso ordenado pelo medium linguístico de argumentos com pressupostos de validade criticáveis, haveria a possibilidade de que as discussões tomassem uma forma de contraposição à razão estratégica; deste modo, a compreensão das ideias, dentro de uma sociedade, é plausível de ser mediada pelo direito moderno, em sua característica integradora, objetivando o aprimoramento das relações intersubjetivas e a garantia de efetiva democracia dentro do Estado de direitos.

Compondo o mundo da vida como fundamental à coordenação e estabilização da ação social, de forma que a ação comunicativa toma a racionalidade como premissa ao pleno entendimento, à intersubjetividade, temos que:

"O mundo da vida, as instituições que surgem naturalmente e o direito têm que amortizar as instabilidades de um tipo de socialização que se realiza através das tomadas de posição [...] com relação a pretensões de validade criticáveis." (HABERMAS, 2003a, p. 25).

Boaventura de Souza santos vê a inclusão da população marginalizada em situações políticas como uma forma a se renovar as práticas societárias, de modo a tornar-se possível a adaptação de tais à realidade social, bem como a dissolução de conflitos, e em prol de decisões e medidas favoráveis as circunstâncias que permeiam os grupos sociais (SANTOS, 2002). A concatenação das práticas políticas com o meio jurídico, ordenando e mediando a interação linguística, pode ser tomada dentro da perspectiva da autolegislação, que, hoje, vem sendo tratada de forma "marginalizada", por assim dizer, com relação à democracia (HABERMAS, 2003b, p. 59-60) - e possui integração pelo medium linguístico.

Neste contexto, Habermas apresenta a teoria do discurso e o conceito procedimental de democracia, levando em conta, mais especificamente, a abordagem das autonomias públicas e privadas a uma "interpretação do processo democrático", garantindo tais autonomias, prevendo, todavia, de antemão, uma articulação dos discursos com base nas experiências de cada grupo socialmente constituído. (SILVA, 2013, p. 88).

\section{CONCLUSÃO}

Com o estudo das premissas e abordagens teóricas, bem como das problemáticas e propostas com embasamento teórico, é possível identificar e verificar a necessidade do aprofundamento das discussões intersubjetivas, bem como do aprimoramento das propostas de políticas deliberativas dentro da estrutura social atual, e que concentrem - de fato - no indivíduo o objetivo do Estado democrático de direito.

Tendo por premissas os processos reconstrutivos das condições da integração social, é possível uma coordenação (ou reordenação) das ações dos indivíduos; a partir do agir comunicativo, no qual está inserida a coordenação, temos a reconstrução e manutenção das ordens sociais, de maneira que seja permitida uma socialização comunicativa pelas pretensões de validade tomadas nas discussões interpessoais.

Desta compreensão do entendimento linguístico, suscitado na força dos atos ilocucionários no mundo da vida, surge, posteriormente, a legitimidade do direito, como medium linguístico, observada não só na coordenação com o Estado, mas na integração dos atores sociais.

Isto posto, temos a racionalidade como premissa a uma legitimação efetiva do Direito e a garantia dos direitos fundamentais, da defesa da dignidade humana a partir do agir comunicativo (razão comunicativa). Habermas, em seus estudos, aponta sua crença no uso racional da comunicação como resposta; vale ressaltar que é, porém, limitante dizer que somente essas 
considerações são bastantes e suficientes a uma política efetiva de manutenção da ordem social que compreenda e respeite a subjetividade de cada indivíduo e trate devidamente a dignidade humana, objetos de estudo que, por sua densidade, não se incluem na presente discussão.

De fato, concluímos no raciocínio de que a representatividade seria devidamente atingida a partir do momento em que o instrumentalismo integrador do direito se pusesse como um elo entre o indivíduo e o Estado, compondo um mecanismo de expressão da vontade social, porém, ainda mais importante e anterior a isso, deveríamos, em nossas relações interpessoais, tomar por base de racionalidade como fator de legitimidade dos discursos intersubjetivos, com fim a estabelecer ou formular uma objetividade, resultando num consenso.

\section{REFERÊNCIAS}

BOBBIO, Norberto. O futuro da democracia: Uma defesa das regras do jogo. Trad.: Marco Aurélio Nogueira. São Paulo: Paz \& Terra: 2015.

DURÃO, Aylton Barbieri. A tensão interna entre facticidade e validade no direito segundo Habermas. In: MARTINS, Clélia Aparecida; POKER, José Geraldo (Org.). O pensamento de Habermas em questão. Marília: Oficina Universitária Unesp, 2008.

. Habermas: os fundamentos do Estado democrático de direitos. Marília:

Trans/Form/Ação. V.32, n. 1, p.119-137, 2009. Disponível em: http://www.scielo.br/scielo.php?script=sci_arttext\&pid=S0101-

317320090000100008\&Ing=en\&nrm=rso Acesso em: 25 de agosto de 2016. http://dx.doi.org/10.1590/S0101-317320090000100008

DWORKIN, Ronald. Levando os direitos a sério. Trad.: Nelson Boeira. São Paulo: Martins Fontes, 2002.

HABERMAS, Jürgen. Pensamento pós metafísico: Estudos filosóficos. Trad.: Flávio Beno Siebeneichler. Rio de Janeiro: Tempo Brasileiro, 1990.

. A inclusão do outro: Estudos de teoria política. Trad.: George Sperber, Paulo Astor Soethe. São Paulo: Loyola, 2002.

Direito e Democracia: Entre facticidade e validade. Vol. I. Trad.: Flávio Beno Siebeneichler. Rio de Janeiro: Tempo Brasileiro, 2003a.

. Direito e Democracia: Entre facticidade e validade. Vol. II. Trad.: Flávio Beno Siebeneichler. Rio de Janeiro: Tempo Brasileiro, 2003b.

SANTOS, Boaventura de S. A Crítica da Razão Indolente - Contra o desperdício da experiência. São Paulo: Cortez, 2000.

SILVA, Luciano Braz da. A função do direito no mundo da vida: linguagem, emancipação e reconhecimento. Revista Direito e Liberdade, Natal, v. 15, n. 3, p. 85-115, set/dez, 2013. Quadrimestral.

Democracia e Comunidade Jurídica: ações, deliberações, ética e responsabilidade. Revista Direito e Práxis, Rio de Janeiro, v. 6, n. 11, 2015, p. 141-172. 